\title{
Anytime Autonomous English MALL App Engagement
}

\author{
https://doi.org/10.3991/ijet.v14i18.10763 \\ Jason Byrne \\ Toyo University, Tokyo, Japan \\ byrnediniad.org
}

\begin{abstract}
Mobile assisted language learning (MALL) apps are often said to be 'Anytime' activities. But, when is 'Anytime' exactly? The objective of the paper is to provide evidence for the when of MALL activity around the world. The research method involved the collection and analysis of an EFL app's time data from 44 countries. The findings were surprising in the actual consistency of usage, 24/7, across 43 of the 44 countries. The $44^{\text {th }}$ country was interesting in that it differed significantly in terms of night time usage. The research also noted differences in Arab, East Asian and Post-Communist country usage, to what might be construed to be a general worldwide app time usage norm. The results are of interest as the time data findings appear to inform the possibility of a potentially new innovative pedagogy based on an emerging computational awareness of context and opportunity, suggesting a possible future language learning niche within the Internet of Things (IoT), of prompted, powerful, short-burst, mobile learning.
\end{abstract}

Keywords-CALL, MALL, EFL, IoT, Post-Communist, Saudi Arabia.

\section{Introduction}

'Learning anytime, anywhere' is one of the most well-known phrases used to describe learning technology [1]. A review of the Mobile Assisted Language Learning (MALL) literature will rapidly bring forth the phrase 'Anytime and anywhere.' But, when exactly is anytime? Is it really $24 / 7$ ? Or, is it more nuanced? For example, does it vary from country to country, day by day or hour by hour? The literature simply does not provide answers. In many MALL research papers to date [2], [3], [4], [5], [6], [7], the word 'Anytime,' seems to refer to the unrestricted potential, 24/7, usage of MALL. There are case studies where the research refers to the time usage of small cohorts of participants [8], [9], [10], [11], although even then, little is stated about when the activities precisely occurred. Indeed, until now, there appears to have been little detailed data on when MALL activity has actually been undertaken. The idea of MALL being an anytime activity seems to be partly an inferred assumption, and partly experiential. This paper provides clear evidence of exactly when one MALL app is being used around the world. 
This research is relevant, as the results could support a future of prompted, powerful, short-burst, mobile learning activities. It could also point to the development of language learning applications for interaction within the Internet of Things (IoT).

The Internet of Things (IoT) is an integrated part of Future Internet including existing and evolving Internet and network developments and could be conceptually defined as a dynamic global network infrastructure with self-configuring capabilities based on standard and interoperable communication protocols where physical and virtual "things" have identities, physical attributes, and virtual personalities, use intelligent interfaces, and are seamlessly integrated into the information network [12 p. 10].

In other words, tomorrow's worldwide network will not only have human users, but electronic device automated users [13]. The things will actually be able to communicate with other things. In addition to being context aware over great distances, it is suggested the mobile Internet will transition to an embedded Internet [14]. It is also very likely that the users will often engage with IoT locally through mobile and wearable devices, connecting to short-range smart sensors, as Broll et al. demonstrated with the Perci framework [15]. This means that IoT can provide real-time and contextualised opportunities for learners to interact with their immediate surrounding environment. This implies that learning opportunities might become available, anytime a person is active, 24/7. In fact, we have the potential to utilise context aware computing [16]. The language learning device, aware of the real world context, presents, via notification, a context and time relevant lesson at that precise moment. This transforms the catchphrase 'Anytime Anywhere' into far more meaningful 'Specific time and specific context.' Eventually, after learning more about the user's behaviour this can be drilled down to 'Most appropriate (efficient) time and most appropriate place.' However, the first step is to understand the basics of the when of 'Anytime' as highlighted in this paper. Once we establish that users are using EFL study apps 24/7, or at least for large and distinct portions of the day, then it becomes meaningful to suggest context aware computing, and IoT, may have a place in the future EFL landscape. However, if there is no concrete evidence that MALL app users are active, using applications $24 / 7$, then why would investors and developers take on the challenge of creating language learning applications that engage IoT 24/7? IoT is expensive, and the high cost of sensors are a general barrier to implementing IoT [17]. Consequently, educational and EFL IoT will require considerable evidence to support the cost of development. This research aims to provide a partial pillar of support for that development. The role of time in contextualising the learning environment should not be underestimated, nor how local culture moulds our individual usage of time. This paper is a first step in understanding the extent to which actual MALL user behaviour indicates potential demand for interaction with the 24/7 availability of IoT and also starts the process of drilling down the specific and most appropriate when, at least, at the country level. The research also points to a specific country where 24/7 English study really means $24 / 7$. 


\section{Methods}

The research focused on data gathered over a 4 month period from one mobile language learning app, using Google Analytics [18], in 44 countries as shown in Table 1. Initially, data was extracted from 370,233 hourly users in 218 countries. This was gradually downsized to focus on 144,620 hourly users in 44 countries. The research also looked at 109,780 daily users in the same 44 countries and over the same time period.

The researcher was the lead developer and co-author of the app which has been recently unpublished. The app was an Android English grammar learning app which had a large user-base; 133,174 distinct devices across 218 countries were recorded accessing the app during the data collection period. The app was fairly simple, it had three distinct levels (beginner, intermediate and advanced) and one mixed level game. In addition, it provided a cheat button for quick answer review and post-game feedback on the right and wrong answer choices. The average user playing time was known to be approximately three to four minutes. The app included a terms of service and privacy statement, where it was stated that data may be gathered and used for research purposes, and users were asked to accept the terms prior to using the app. Furthermore, the extracted data was anonymous. The researcher made no attempt to tag the data to actual people. Once the data had been downloaded to the research computer, the collected and collated data was deleted from the researcher's Google analytic account. Therefore, there is no obvious way, apparent, to associate the collated data with actual people through the misuse, or hacking into, the researcher's accounts or computers.

In understanding the data, it should be made clear that a user, according to Analytics Help [19], is defined as a device, uniquely identified as using a specific hourly or daily segment. For example, if one person were to use five hourly segments, on ten occasions for each hour, in the data they would have been counted as five users. In other words, the user would have been defined, multiple times, as one user for each hourly segment. In fact, it is known that the 370,233 hourly users were comprised of 133,174 actual device users.

Repeat visits by a user to the same hourly segment would normally not have been counted. However, the data has certain limitations. The data can not reveal if multiple real human being users were sharing the same device; they would have been counted as one device user. So in this scenario, the research may have under-counted the number of users. Equally, it is possible that if a device has been reset, then one user could be counted multiple times, as they would receive a new unique identifying tag after each reset. In this scenario, the research may have over-counted the number of users.

The 44 countries selected for analysis were chosen using the following criteria. The country required at least 1000 hourly users, as defined above, over the four month period. This criteria narrowed the selection from 218 countries to a more manageable 64. The next phase of selection involved time comparison issues. The gathered time data was set to coordinated universal time (UTC). This data needed to be re-calculated in local time. This was achieved using world clock data [20]. However, since the data was organised in one hour chunks, any country with fractional hour time-zone differ- 
ences from UTC could not be used. For example, Afghanistan is four and half hours, India is five and half hours, Iran three and half hours, Nepal is five hours and forty five minutes, Myanmar six and half hours and Sri Lanka six and a half hours, all ahead of UTC. It was not possible to use these countries as we could not accurately reproduce local time data in precise one hour chunks. Furthermore, the data collection period occurred wholly within the daylight saving summertime period and was unlikely to be a serious issue, but to enhance neighbouring country data comparability, Asian and African countries using daylight savings were eliminated from selection to increase comparability of neighbouring nations within their regions. This meant, Israel, Jordan, Morocco and Syria were removed from selection. In contrast, all of the selected European countries use daylight savings and consequently they were kept. This issue did not affect the Americas selection due to other larger complications.

Finally, there was the issue of multiple time-zone nations and nations that probably should have multiple time-zones. For example, Indonesia has three time-zones and Kazakhstan has two time-zones, these were eliminated from selection as the local time data, at country level, could not be calculated. This could have been overcome by collecting the data at city level, but this would have changed the fundamental parameters of the project. The project would have become city rather than country focused. The time-zone issue has had a huge impact on the Americas; Brazil, Canada, Mexico and the United States have had to be deselected leaving only Colombia in the data set. It has also meant that there is no representative of Oceania in the data, as Australia was deselected. This issue also affected the selection of Russia and Ukraine within Europe. In fact, the same issue affected Russia's selection within Asia too. In contrast, China and Malaysia both have singular time-zones, but a simple glance at the map of the world tells its own story. China's southern neighbours cross at least three timezones and Malaysia's northern neighbours cross at least two time-zones. Consequently, comparing China and Malaysia with other countries would not be comparing like with like. The author knows from experience in western China, that operating on Beijing time, the local people simply start later and go to bed later, following the rhythms of the sun and not the clock. Therefore, it was decided, China and Malaysia should be eliminated from selection due to difficulties in making international comparisons. At this stage, there were 44 countries in the selection pool.

Table 1. 44 countries across 11 time-zones

\begin{tabular}{|l|c|l|l|c|c|}
\hline \multicolumn{1}{|c|}{ Africa } & UTC+ & \multicolumn{1}{c|}{ Asia } & UTC+ & n \\
\hline Ghana & 0 & 1,806 & Turkey & 2 & 3,227 \\
\hline Guinea & 0 & 1,438 & Saudi Arabia & 3 & 4,871 \\
\hline Liberia & 0 & 1,308 & Yemen & 3 & 1,399 \\
\hline Mali & 0 & 1,875 & Oman & 4 & 1,214 \\
\hline Senegal & 0 & 2,524 & UAE & 4 & 2,212 \\
\hline Algeria & 1 & 2,859 & Pakistan & 5 & 7,385 \\
\hline Angola & 1 & 2,400 & Tajikistan & 5 & 2,368 \\
\hline Cameroon & 1 & 2,028 & Turkmenistan & 5 & 4,979 \\
\hline Côte d'Ivoire & 1 & 1,653 & Kyrgyzstan & 6 & 1,751 \\
\hline Nigeria & 1 & 6,916 & Uzbekistan & 6 & 14,052 \\
\hline Egypt & 2 & 4,631 & Cambodia & 7 & 2,468 \\
\hline
\end{tabular}




\begin{tabular}{|c|c|c|c|c|c|}
\hline Libya & 2 & 1,973 & Thailand & 7 & 4,472 \\
\hline South Africa & 2 & 1,345 & Vietnam & 7 & 2,053 \\
\hline Ethiopia & 3 & 7,997 & Hong Kong & 8 & 1,359 \\
\hline Kenya & 3 & 1,099 & Philippines & 8 & 14,899 \\
\hline Somalia & 3 & 3,668 & Taiwan & 8 & 2,460 \\
\hline South Sudan & 3 & 2,163 & South Korea & 9 & 1,662 \\
\hline Sudan & 3 & 6,575 & Japan & 9 & 2,988 \\
\hline \begin{tabular}{|l|} 
Europe \\
\end{tabular} & UTC+ & $\mathbf{n}$ & Americas & UTC+ & $\mathbf{n}$ \\
\hline $\mathrm{UK}^{1}$ & 1 & 3,393 & Colombia & -5 & 1,303 \\
\hline Czech Republic $^{1}$ & 2 & 1,060 & \multicolumn{3}{|c|}{$\mathrm{N}=144,620$} \\
\hline France $^{1}$ & 2 & 1,683 & Africa & & 54,258 \\
\hline Germany $^{1}$ & 2 & 2,237 & Asia & & 75,819 \\
\hline Italy $^{1}$ & 2 & 1,913 & Europe & & 13,240 \\
\hline Poland $^{1}$ & 2 & 1,091 & \multirow{2}{*}{ The Americas } & & \multirow{2}{*}{1,303} \\
\hline Spain $^{1}$ & 2 & 1,863 & & & \\
\hline
\end{tabular}

1. Daylight savings time

\section{$3 \quad$ Results}

If daily app usage was spread evenly across the 24 hours of the day, we would see a distribution of $4.2 \%$ per hour. Looking at Figure 1, we see that not one of the 44 countries breaks an hourly peak of $8 \%$ and no hourly bottom ever reaches $0 \%$. This MALL app really does get used anytime, is surprisingly even across the 24 hours of the day, and strikingly similar across the four continents.

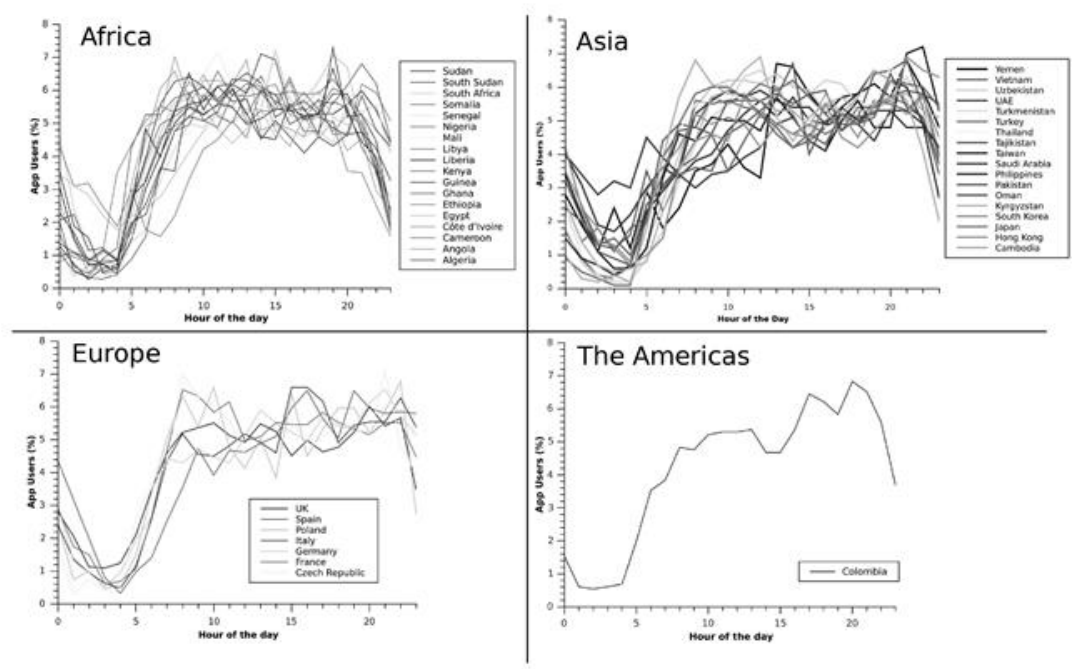

Fig. 1. Mobile app usage distribution across four continents per hour of the day

The app usage throughout the day between 08:00 22.59 is remarkably even, the lowest number of hourly users during this time period was 6,890 and the highest 
8,179. Usage then falls from 5,288 during the hour 23:00 23:59 to 2,218 during the hour 01:00 01:59. The data shows that the lowest period in the 24 hour cycle is between 02:00 4:59 with an absolute low of 1,185 hourly users between 03:00 3:59. Starting at 05:00 until 07:59 activity starts to build from 2,881 users to 5,643 users. Also, while each country had its own mini-peaks, collectively there are two peak periods between 11:00 14:59 and 19:00 21:59. Please see the totals at the bottom of Appendix A for details.

Overall, the data suggests the peaks and troughs of mobile app usage follow the ebb and flow of modern life around the globe. People and app activity seem to begin to awake at 05:00 and most people are asleep, and most devices are inactive, by 02:00. The small peaks, around lunchtime and in the evening, are consistent with the expectation that more people have free-time at these times. The most interesting observation is how users find time throughout the day. The app, it appears we can confirm, was really being used anytime that the user had the time or was prompted to use it. Clearly day and evening usage, unsurprisingly, yet nevertheless can be confirmed, is much higher than late night early morning usage across all 44 countries. The day and evening data (see Appendix B) when represented as quarters, shows Q3 (12:00 17:59) to be remarkably consistent across all 44 countries with a high of $36.94 \%$ and a low of $28.05 \%$. That said, the most unexpected take away was the number of people who do use the app in the middle of the night. In fact, approximately $8.7 \%$ of the total users (see Appendix B) were using the app in the first quarter (Q1), of the day, between midnight and 05:59. This is approximately 1 in 12 users. This nocturnal app activity was far higher than had been anticipated and, as can be seen in Figure 2, confirms that this English study app is used anytime.

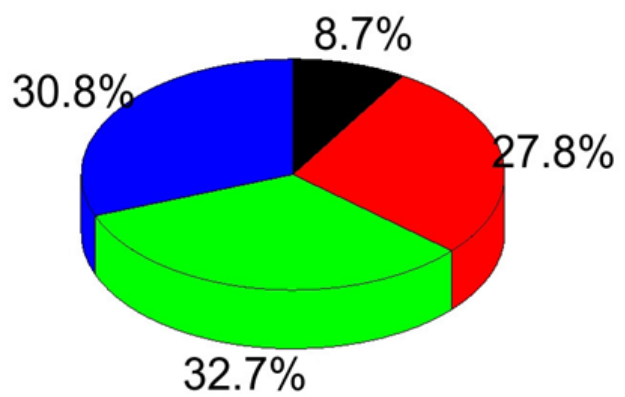

Fig. 2. 24 hour mobile app usage in quarterly 6 hour periods for 44 countries 
As can be seen from Figure 1, generally all 44 countries appear to follow the same flow of daily app activity. According to Appendix B, 26 countries, late night, Q1 usage falls within a fairly narrow range of $6 \% \sim 11.00 \%$. However, the data shows that 13 of the 18 countries that fall outside of this range, belong to regional or cultural clusters that suggest a more nuanced layer of meaning in the data. For example, $11.25 \%$ of total East Asian usage occurs between 00:00 05:59, more specifically in Hong Kong (11.26\%), Japan (12.42\%), South Korea (12.33\%) and Taiwan (9.02\%). This elevated night time pattern is even more true of the Arab nations across North Africa and the Middle East. In the six hours after midnight, percentage of total usage for Algeria (9.55\%), Egypt (15.57\%), Libya (17.94\%), Oman (12.85\%), Saudi Arabia (20.84\%), UAE (15.87\%) and Yemen (12.29\%) leads to an average after midnight usage of $14.99 \%$. At the opposite end of the regional spectrum, according to Appendix B, the Central Asian republics have very low Q1, 00:00 5:59, usage; Kyrgyzstan $(6.62 \%)$, Tajikistan $(4.05 \%)$, Turkmenistan $(5.00 \%)$ and Uzbekistan $(6.76 \%)$ with a combined average of $5.61 \%$.

At a glance, at Appendix B, it might appear low income countries [21], such as Cambodia (3.89\%), Ethiopia (5.35\%) and Tajikistan (4.05\%) tend to have lower than average Q1 usage, but this cannot be fully substantiated. Guinea (10.64\%), Liberia (9.25) and Mali (9.87\%) are also low income nations, but have above average Q1 usage. In fact, see Table 2, national income appears to play a much smaller role in defining Q1 usage than may first appear. The data is actually relatively evenly split across the four income types. 22 countries are defined as low or lower middle income and 22 countries are defined as upper middle or high income [21]. However the low and lower middle income countries only account for 12 of the bottom 22 ranked Q1 countries and a rather significant 10 of the 22 top ranked Q1 countries. Therefore, while it is true that the data does skew towards high income greater Q1 usage and low income less Q1 usage, the finding is somewhat marginal and not persuasive.

Table 2. National income as indicator of late night usage among the 44 countries

\begin{tabular}{|l|c|c|c|}
\hline \multicolumn{1}{|c|}{ National Income Type } & Bottom 22 & Top 22 & Totals \\
\hline Low & 7 & 4 & 11 \\
\hline Low Middle & 5 & 6 & 11 \\
\hline Upper Middle & 5 & 3 & 8 \\
\hline High* & 5 & 9 & 14 \\
\hline & 22 & 22 & 44 \\
\hline
\end{tabular}

National income data [21]

*Includes Taiwan's national income data [22].

However, there does appear to be a pattern based on a nation's current or former status as self-declared Marxist-Leninist Socialists, or more simply, communists [23]. Communist and former communist countries tend to use the English language learning app significantly less after midnight than non-communist nations. Ranking the 44 countries by Q1 usage, the post-communist nations of Angola, Cambodia, Czech Republic, Ethiopia, Kyrgyzstan, Poland, Somalia, Tajikistan, Turkmenistan, Uzbekistan, and still communist Vietnam, account for 11 of the lower ranked 22 nations. This 
sharply contrasts with the top 22 nations where only Yemen was once a communist country. See Table 3.

Table 3. Historical communist national identification as indicator of late night usage

\begin{tabular}{|l|c|c|c|}
\hline \multicolumn{1}{|c|}{ Communist* } & Bottom Ranked 22 & Top Ranked 22 & Totals \\
\hline Yes & 11 & 1 & 12 \\
\hline No & 11 & 21 & 32 \\
\hline & 22 & 22 & 44 \\
\hline
\end{tabular}

* The term Communist refers to countries that have previously self-declared, or still do self-declare, as Marxist-Leninist socialist nations [23].

It is possible to hypothesise, given these differences, that anytime, in these 44 cases, reflects the nuance in local cultural norms and practices. Indeed, the rhythm of app usage is probably quite reflective of the rhythm of life in all 44 countries. Please see Figure 3 and Appendices B \& C.
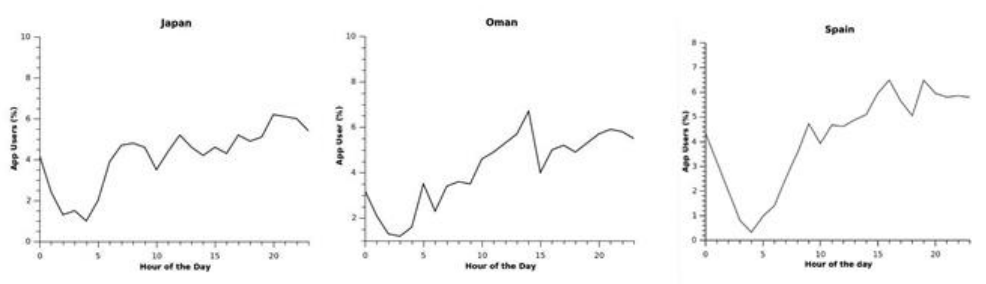

Fig. 3. Examples of nuanced mobile app usage distribution per hour of the day

Saudi Arabia, in particular, stands out when it comes to anytime 24/7 MALL. Saudi Arabian app usage, as seen in Figure 4, only fluctuates between $2.8 \%$ and $5.4 \%$ of total usage per hour, providing a range of 2.6 percentage points across the 24 hour period of the day. This is significantly less than the median average range for the 18 Asian countries of about 6 percentage points. The graph in Figure 4 is exceptionally flat in comparison to all other countries studied, see Appendix C, signifying the evenness of usage across the 24 hours of the day. The pie chart in Figure 4 reinforces this assertion of even 24 hour usage.
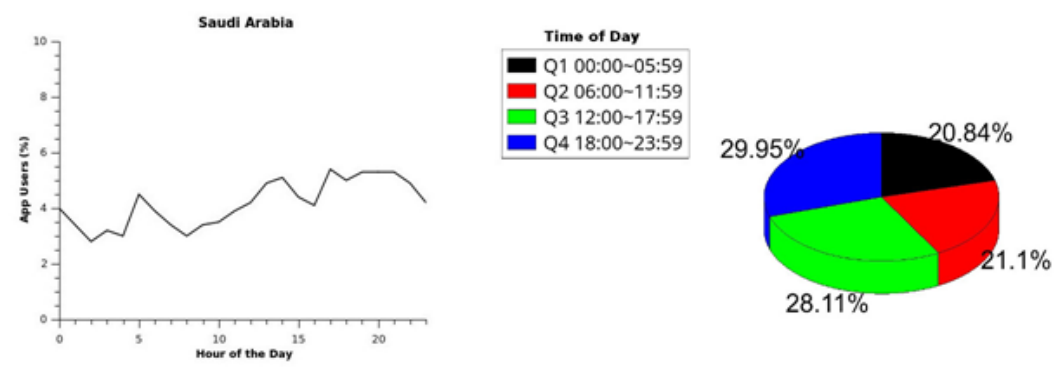

Fig. 4. Saudi Arabian 24 hour mobile app usage per hour and daily quarters 
Table 4 shows the difference between global and Saudi Arabian night time usage. In Saudi Arabia users are more than three times more likely to use the app between 2:00 and 4:59 than the global average.

Table 4. Global Saudi Arabian hourly night usage comparison as percentage of $24 \mathrm{hr}$ period

\begin{tabular}{|l|c|c|c|c|}
\hline \multicolumn{1}{|c|}{ Location/Time } & $\mathbf{2 : 0 0} \sim \mathbf{2 : 5 9}$ & $\mathbf{3 : 0 0} \sim \mathbf{3 : 5 9}$ & $\mathbf{4 : 0 0} \sim \mathbf{4 : 5 9}$ & $\mathbf{2 : 0 0} \sim \mathbf{4 : 5 9}$ \\
\hline Global & $1 \%$ & $0.8 \%$ & $0.9 \%$ & $2.7 \%$ \\
\hline Saudi Arabia & $2.8 \%$ & $3.2 \%$ & $3 \%$ & $9 \%$ \\
\hline
\end{tabular}

In taking a weekly view, see Table 5, we see little change from day to day. The daily distribution over the week is extremely even. When we look at the distribution of the 109,780 weekly users, the weekly low is $13.93 \%$ and the high is $14.76 \%$, meaning that the range is a surprisingly low 0.83 percentage points. This means that there is no significant difference, on a global scale, between the days of the week.

Table 5. Percentage distribution of app users across 44 countries per day of the week

\begin{tabular}{|l|c|c|c|c|c|c|c|}
\hline & Sun & Mon & Tues & Wed & Thu & Fri & Sat \\
\hline Users & 14.16 & 13.94 & 13.93 & 14.76 & 14.61 & 14.57 & 14.03 \\
\hline
\end{tabular}

$\mathrm{N}=109,780$

If we focus on the individual 44 countries, see Figure 5, we do find more local variation, with daily usage from $11.58 \%$ to $17.11 \%$ of the weekly total. Over $90 \%$ of the time, the daily distribution for each country was between $13 \%$ and $16 \%$. In precisely three quarters of cases, across the 44 countries, the distribution fell between a very narrow band of $13 \%$ to $15 \%$. Given that $14.28 \%$ per day would provide an even distribution and a range of zero, the results are significantly and surprisingly even across the week. Please see Appendix D.

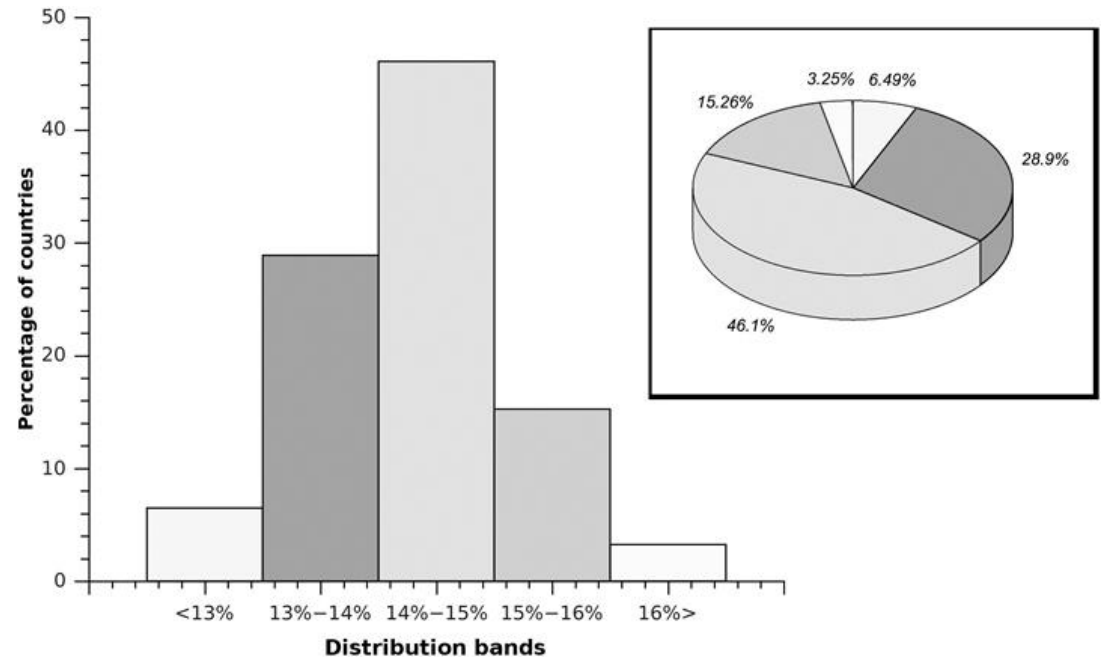

Fig. 5. Percentage of 44 countries found across per day distribution bands 


\section{Discussion}

The results provide a concrete view of what 'Anytime' in MALL actually means. It is clear that users, from 44 countries, use the app relatively equally across the week. In terms of time of day, once again, 'Anytime' probably does literally mean anytime for at least some people in each country. While it is true, that unsurprisingly, usage tails off during the night, more surprisingly, there was never an hour when someone did not use the app in any of these 44 countries during the entire 4 month research data collection period. Whenever a person might feel comfortable using a mobile phone, it seems likely that they might be willing to study English at this time. The smallness of the range, and the relative evenness of the distribution, over the 24 hours of the day, suggests people find time for, or possibly fill time with, language learning activities. The results also suggest, that a lull in usage corresponds to sleeping activity, and peaks, where they exist, tend to correspond to traditional evening free time activity and lunchtime. This might also suggest that the app is generally used whenever a person finds that they have free-time rather than generally orchestrated by a teacher or learning environment.

Saudi Arabia provided the most interesting data with users approximately three times more likely to use the app during the four hours after midnight than the overall average. Consequently, Saudi Arabia provided a contrast with most of the other 43 countries, in that there seemed to be little distinction between day and night time usage. This suggests that Saudi Arabia could provide a unique testing environment for future EFL 24/7 research and technological development.

There appear to be two regional cultural clusters of high late night usage, in the Arab states and East Asia. A third regional cluster in Central Asia displays low late night usage, although this may be connected to a cluster based on socio-economic ideology. Former and current Marxist-Leninist socialist, or communist nations, still seem to share cultural similarities forged from their prior common ideology, and differences when compared to the rest of the world, and this is reflected in their usage of time, specifically when they decide to play an English grammar app. The why of these four distinct patterns can not be addressed in this paper, but the evidence exists to justify, and prompt, further research, and discussion, that will seek to explain these findings.

Most importantly, the results of this 'Anytime' research may inform future application development and self-study learning approaches and pedagogies. The likely timefilling environmentally prompted behaviour of the verified 24/7 app usage, may, for example, lend itself to syncing with IoT. If the evidence points to users using a grammar app at 03:00 or 15:00, then a new IoT based pedagogical model built on awareness of the user context (Where are they? What are they doing? Who are they with?) and the time that the social activity is occurring, thus means a potential timely opportunity can be created. For example, a home motion sensor, detecting movement at three in the morning, might trigger a "Since You Are Awake" learning activity. The uses are infinite, and consequently there must be a question, as we see with apps and social media today, of how users will react to a constant stream of prompts and notifications. Clearly, some will be ignored and others engaged. An understanding of the specific time, as opposed to the vagueness of anytime, of user engagement, is a vital 
part of honing development on the most efficient usage cases, thereby minimising the need to notify at inappropriate moments. For example, the suggested late night IoT sensor based learning activity would seem, as seen in the results (Appendix B), far more appropriate to Saudi Arabia than Cambodia. It seems probable that five times as many Saudi users would make use of this activity than Cambodians. The cost of IoT development makes it important that time specific activity hot spots are discovered and focused upon.

\section{Conclusion}

A nuanced global understanding of the interaction between time and local culture, within the context of glocalization, could inform a new innovative international MALL based pedagogy. The emerging computational user context awareness (when, where and what), provided by IoT, aligned with small pockets of known user app study-time, 24/7, could generate prompted, powerful, short-burst, mobile learning opportunities. These learning opportunities could be global in reach, but would be culture and user specific in terms of the when, where and what. As this study shows, time is a reachable plank of computational context awareness and a greater understanding of this could potentially intensify the impact of emerging IoT learning innovation in the very near future.

\section{References}

[1] L. H. Wong, W. Chen, and M. Jan, "How artefacts mediate small-group co-creation activities in a mobile-assisted seamless language learning environment?" Journal of Computer Assisted Learning, vol. 28, no. 5, pp. 411-424, 2012. https://doi.org/10.1111/j.1365-2729. 2011.00445.x

[2] J. Juhary, "Revision through Twitter: Do tweets affect students' performance?" International Journal of Emerging Technologies in Learning, vol. 11, no. 4, pp. 4-10, 2016. Online]. Available: https://doi.org/10.3991/ijet.v11i04.5124

[3] H. Y. Kim, and Y.H. Kwon, "Exploring smartphone applications for effective mobileassisted language learning," Multimedia-Assisted Language Learning, vol. 15, no. 1, pp. 31-57, 2012.

[4] A. Kukulska-Hulme, and L. Shield, "An overview of mobile assisted language learn ing: Can mobile devices support collaborative practice in speaking and listening," ReCALL, vol. 20, no. 3, pp. 1-20, 2007.

[5] L. Liu, L. Zhang, P. Ye, and Q. Liu, "Influence factors of satisfaction with mobile learning app: An empirical analysis of China," International Journal of Emerging Technologies in Learning, vol. 13, no. 3, pp. 87-99, 2018. [Online]. Available: https://doi.org/10.3991/ijet. $\underline{v 13 i 03.8381}$

[6] V. Persson, and J. Nouri, "A systematic review of second language learning with mobile technologies," International Journal of Emerging Technologies in Learning, vol. 12, no. 2, pp.188-210, 2018. [Online]. Available: https://doi.org/10.3991/ijet.v13i02.8094 
[7] L. H. Wong, and C.K. Looi, "What seams do we remove in mobile-assisted seamless learning? A critical review of the literature," Computers \& Education, vol. 57, no. 4, pp. 2364-2381, 2011. https://doi.org/10.1016/j.compedu.2011.06.007

[8] C.K. Hsu, G.J. Hwang, and C.K. Chang, “A personalized recommendation-based mobile learning approach to improving the reading performance of EFL students," Computers \& Education, vol. 63, pp. 327-336, 2013. https://doi.org/10.1016/j.compedu.2012.12.004

[9] H. Jarvis, and M. Achilleos, "From computer assisted language learning (CALL) to mobile assisted language use (MALU)," Tesl-ej, vol. 16, no. 4, pp. 1-18, 2013.

[10] M. Lu, "Effectiveness of vocabulary learning via mobile phone," Journal of Computer Assisted Learning, vol. 24, no. 6, pp. 515-525, 2008. https://doi.org/10.1111/j.1365-2729. 2008.00289.x

[11] L. H. Wong, and C.K. Looi, "Vocabulary learning by mobile-assisted authentic content creation and social meaning-making: Two case studies," Journal of Computer Assisted Learning, vol. 26, no. 5, pp. 421-433, 2010. https://doi.org/10.1111/j.1365-2729.2010.00 $\underline{357 . x}$

[12] O. Vermesan et al., "Internet of things strategic research roadmap," Internet of Things-Global Technological and Societal Trends, vol. 1, pp. 9-52, 2011.

[13] L. Srivastava et al., "The Internet of things," International Telecommunication Union Internet Reports, Geneva, Switzerland, 2005.

[14] G. Wu, S. Talwar, K. Johnsson, N. Himayat, and K.D. Johnson, "M2M: From mobile to embedded Internet," IEEE Communications Magazine, vol. 49, no. 4, pp. 36-43, 2011. https://doi.org/10.1109/mcom.2011.5741144

[15] G. Broll, E. Rukzio, M. Paolucci, M. Wagner, A. Schmidt, and H. Hussmann, "Perci: Pervasive service interaction with the Internet of things," IEEE Internet Computing, vol. 13, no. 6, pp. 74-81, 2009. https://doi.org/10.1109/mic.2009.120

[16] C. Perera, A. Zaslavsky, P. Christen, and D. Georgakopoulos, "Context aware computing for the Internet of things: A survey," IEEE Communications Surveys \& Tutorials, vol. 16, no.1, pp. 414-454, 2014. https://doi.org/10.1109/surv.2013.042313.00197

[17] K.A. Al Rabaiei, and S. Harous, 'Internet of things: Applications and challenges," In 2016 12th International Conference on Innovations in Information Technology (IIT), 2016, pp. 212-216. https://doi.org/10.1109/innovations.2016.7880054

[18] "Google Analytics." [Online]. Available: https://marketingplatform.google.com/about/anal ytics/ [Accessed March 5, 2019].

[19] "Analytics Help.” Available: https://support.google.com/analytics/answer/6083676?hl=en [Accessed March 5, 2019].

[20] S. Thorsen, "The World Clock." http://www.timeanddate. com/worldclock [Accessed March 5, 2019].

[21] World Bank Group, The Little Green Data Book. Washington, DC: World Bank Pub lications, 2014. [Online]. Available: https://doi.org/10.1596/978-1-4648-0175-4

[22] World Bank Group, "World Bank Country and Lending Groups," The World Bank. http://datahelpdesk.worldbank.org/knowledgebase/ar ticles/906519\#High_income/ [Accessed August 31, 2018.] https://doi.org/10.1596/30977

[23] "List of socialist states." Wikipedia.: https://en.wikipedia.org/w/index.php?title=List_of socialist states\&oldid=856639331 Accessed August 30, 2018].

\section{$7 \quad$ Acknowledgement}

Thank you to Eltsoft LLC and R. Diem. 


\section{Author}

Jason Byrne is an Associate Professor within the Department of Information Networking for Innovation and Design at Toyo University, Tokyo, Japan. His research interests include CALL, mobile assisted language learning and the Internet of things.

Article submitted 2019-04-29. Resubmitted 2019-06-20. Final acceptance 2019-06-20. Final version published as submitted by the authors. 


\section{$9 \quad$ Appendices}

\subsection{Appendix A: User totals for 44 countries per hour of the day}

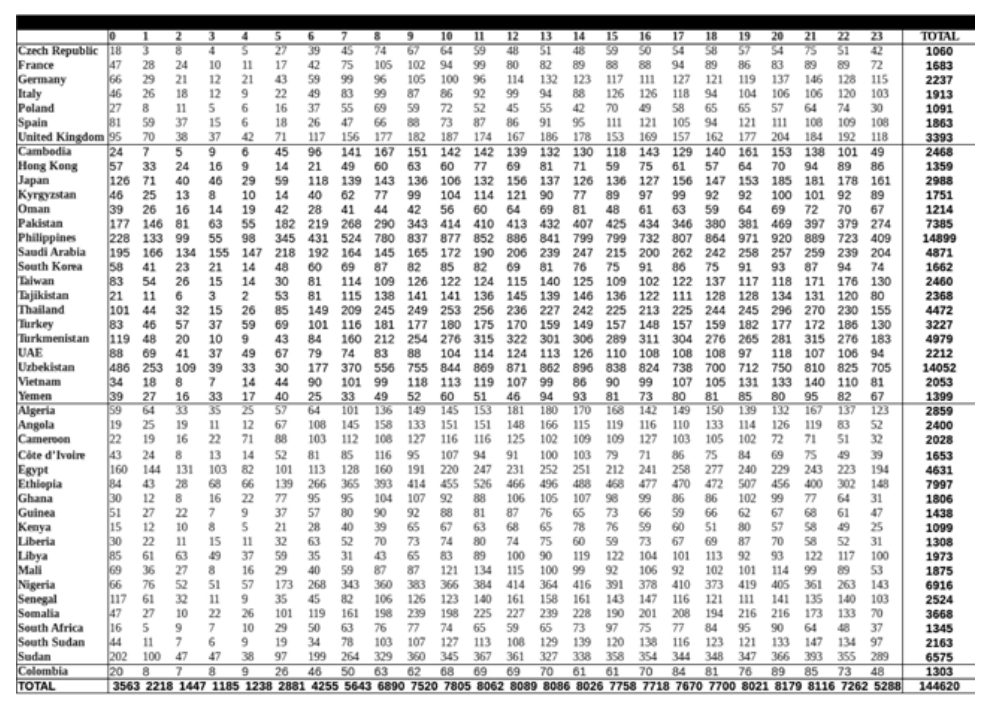


9.2 Appendix B: User percentage totals for 44 countries in six hour daily quarters

\begin{tabular}{|c|c|c|c|c|c|c|}
\hline \multicolumn{2}{|l|}{ Totals } & & \multicolumn{4}{|c|}{ Time (\%) } \\
\hline Country & $N=$ & & Q1 & Q2 & Q3 & Q4 \\
\hline & & & $(0.00-5.59)$ & $(6.00-11.59)$ & $(12.00-17.59)$ & $(18.00-23.59)$ \\
\hline Cambodia & 2468 & & 3.89 & 34 & 32.05 & 30.06 \\
\hline Tajikistan & 2368 & & 4.05 & 31.76 & 33.74 & 30.45 \\
\hline South Sudan & 2163 & & 4.44 & 25.98 & 34.67 & 34.91 \\
\hline Turkmenistan & 4979 & & 5 & 26.13 & 36.81 & 32.05 \\
\hline Ethiopia & 7997 & & 5.35 & 30.25 & 35.83 & 28.57 \\
\hline South Africa & 1345 & & 5.65 & 30.11 & 33.16 & 31.08 \\
\hline Colombia & 1303 & & 5.99 & 27.48 & 31.85 & 34.69 \\
\hline Metnam & 2053 & & 6.09 & 31.17 & 28.64 & 34.1 \\
\hline Czech Republic & 1060 & & 6.13 & 32.83 & 29.25 & 31.79 \\
\hline Somalia & 3668 & & 6.35 & 31.08 & 35.25 & 27.32 \\
\hline Angola & 2400 & & 6.38 & 35.25 & 32.25 & 26.13 \\
\hline Philippines & 14899 & & 6.43 & 28.87 & 32.65 & 32.06 \\
\hline Kenya & 1099 & & 6.46 & 27.48 & 36.94 & 29.12 \\
\hline Kyrgyzstan & 1751 & & 6.62 & 28.33 & 32.72 & 32.32 \\
\hline Poland & 1091 & & 6.69 & 31.53 & 29.24 & 32.54 \\
\hline Uzbekistan & 14052 & & 6.76 & 25.41 & 35.79 & 32.04 \\
\hline Thailand & 4472 & & 6.78 & 30.43 & 30.59 & 32.2 \\
\hline Nigeria & 6916 & & 6.87 & 30.42 & 34.31 & 28.4 \\
\hline Italy & 1913 & & 6.95 & 25.93 & 34.03 & 33.09 \\
\hline Sudan & 6575 & & 8.08 & 28.35 & 31.67 & 31.91 \\
\hline France & 1683 & & 8.14 & 30.72 & 30.96 & 30.18 \\
\hline Germany & 2237 & & 8.58 & 24.81 & 32.36 & 34.24 \\
\hline Taiwan & 2460 & & 9.02 & 27.48 & 28.98 & 34.51 \\
\hline Ghana & 1806 & & 9.14 & 32.17 & 33.28 & 25.42 \\
\hline Liberia & 1308 & & 9.25 & 31.5 & 31.19 & 28.06 \\
\hline Cote divoire & 1653 & & 9.32 & 34.97 & 32.06 & 23.65 \\
\hline Pakistan & 7385 & & 9.53 & 26.32 & 33.27 & 30.87 \\
\hline Algeria & 2859 & & 9.55 & 26.16 & 34.63 & 29.66 \\
\hline Mali & 1875 & & 9.87 & 28.16 & 32.21 & 29.76 \\
\hline United Kingdom & 3393 & & 10.4 & 29.27 & 29.77 & 30.56 \\
\hline Senegal & 2524 & & 10.5 & 24.64 & 35.1 & 29.75 \\
\hline Guinea & 1438 & & 10.64 & 33.94 & 29.62 & 25.8 \\
\hline Turkey & 3227 & & 10.88 & 28.82 & 29.13 & 31.17 \\
\hline Hong Kong & 1359 & & 11.26 & 24.28 & 30.61 & 33.85 \\
\hline Spain & 1863 & & 11.59 & 20.77 & 32.69 & 34.94 \\
\hline Cameroon & 2028 & & 11.74 & 33.63 & 33.28 & 21.35 \\
\hline Yemen & 1399 & & 12.29 & 19.3 & 33.38 & 35.03 \\
\hline South Korea & 1662 & & 12.33 & 27.98 & 28.76 & 30.93 \\
\hline Japan & 2988 & & 12.42 & 25.9 & 28.05 & 33.63 \\
\hline Oman & 1214 & & 12.85 & 22.32 & 31.8 & 33.03 \\
\hline Egypt & 4631 & & 15.57 & 22.87 & 31.2 & 30.36 \\
\hline UAE & 2212 & & 15.87 & 24.5 & 31.15 & 28.48 \\
\hline Libya & 1973 & & 17.94 & 17.54 & 32.24 & 32.29 \\
\hline Saudi Arabia & 4871 & & 20.84 & 21.1 & 28.11 & 29.95 \\
\hline $\mathrm{N}=$ & 144620 & Average & 8.67 & 27.78 & 32.74 & 30.82 \\
\hline
\end{tabular}


Paper-Anytime Autonomous English MALL App Engagement

9.3 Appendix C: Graphs of $\mathbf{4 3}$ countries from Africa, Asia and Europe

Africa

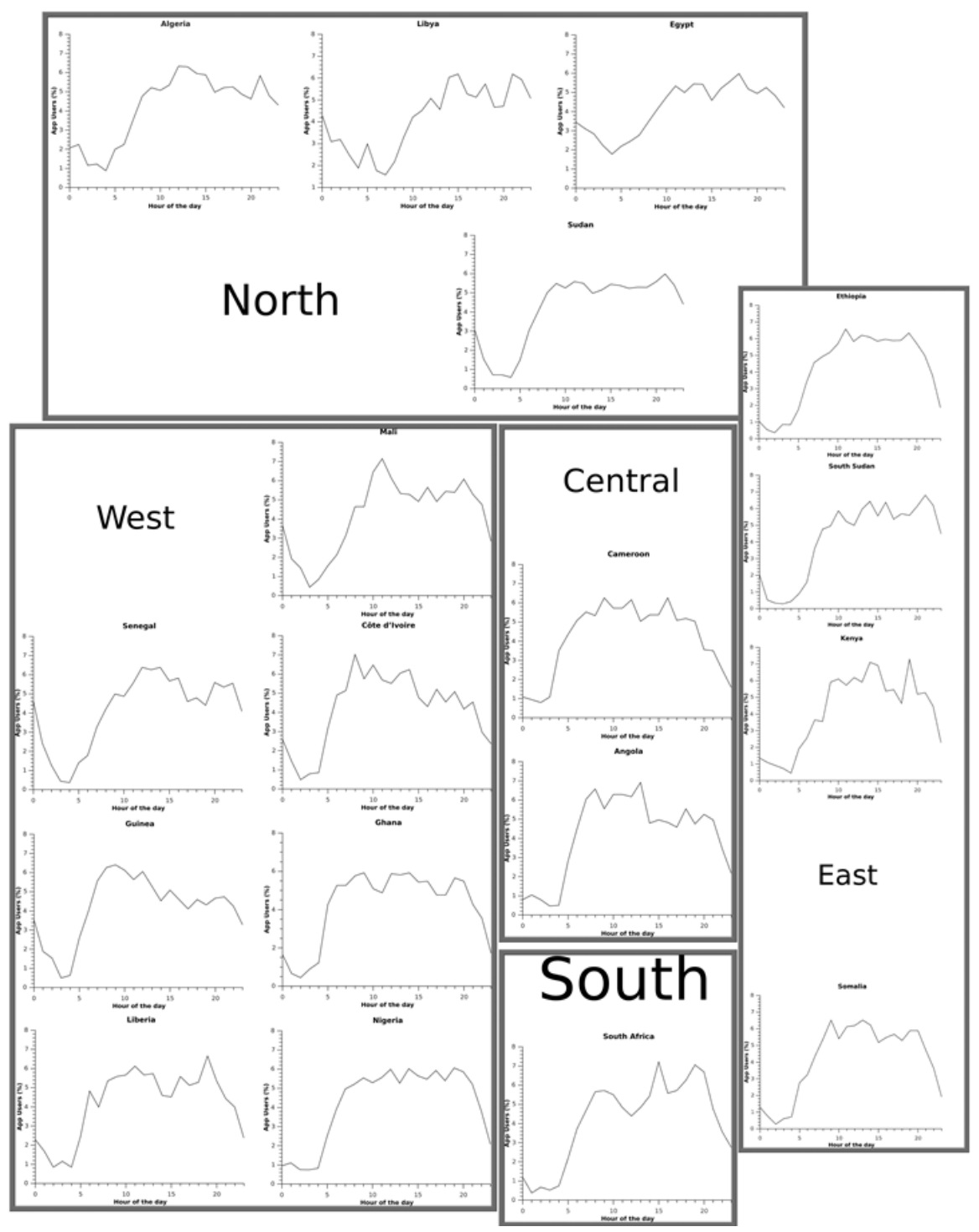


Paper-Anytime Autonomous English MALL App Engagement

Asia

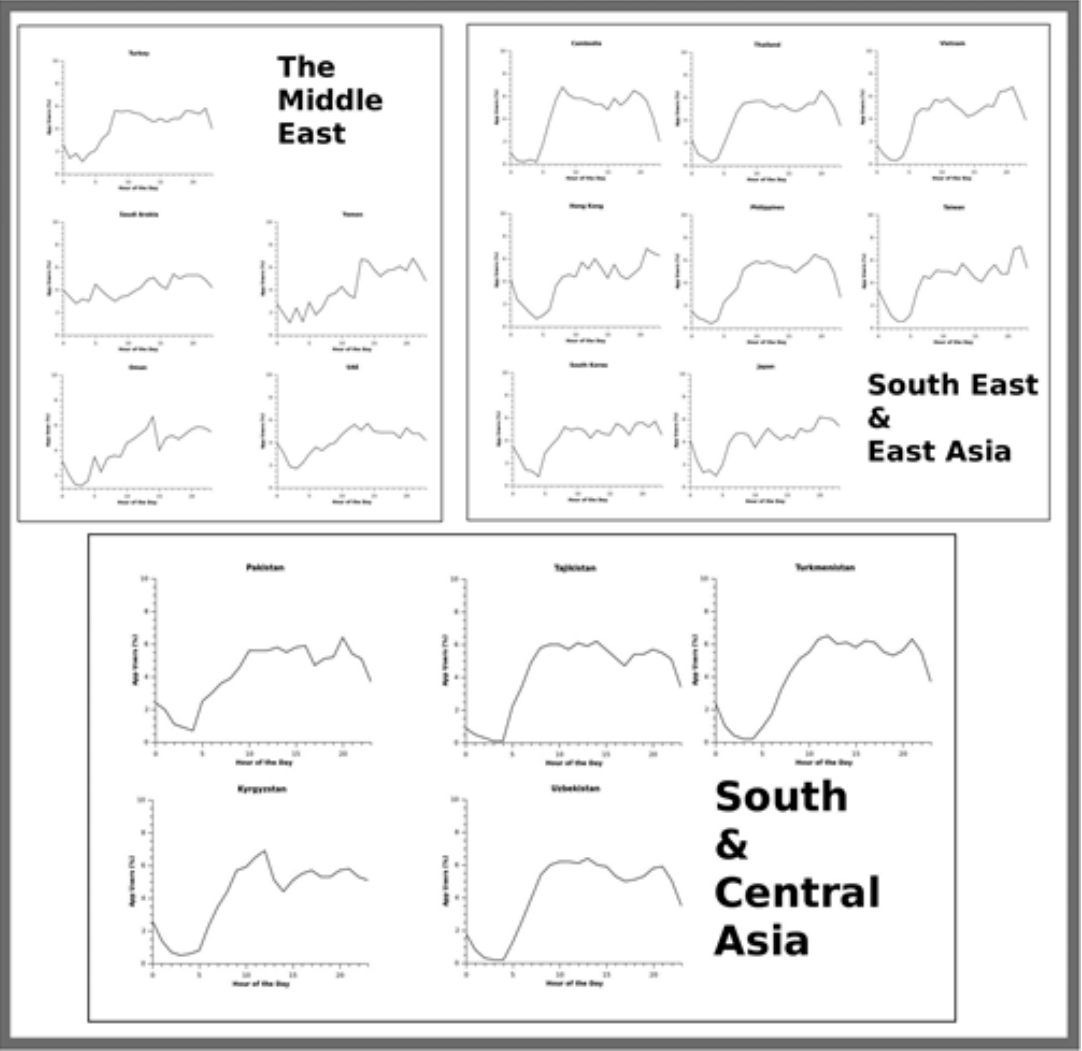




\section{Europe}

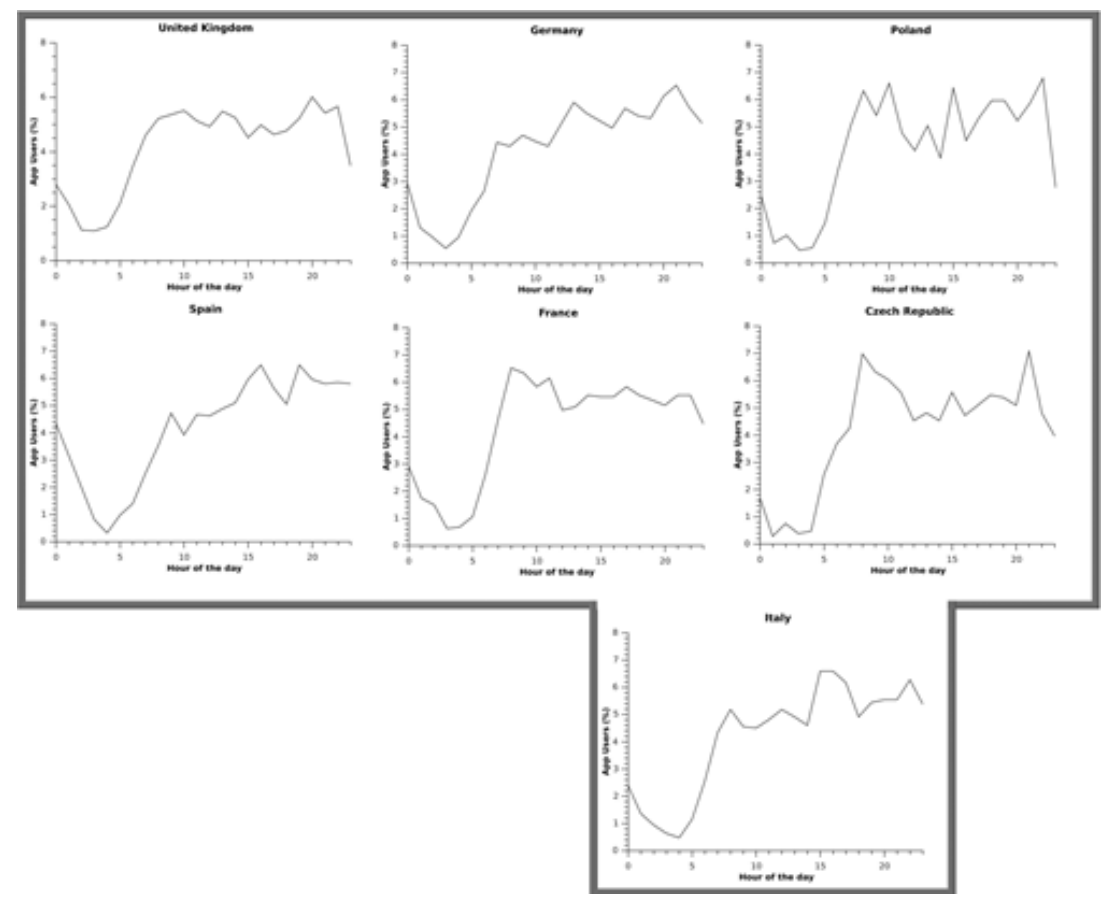

Americas: There is only 1 nation in the Americas sample. The graph for Colombia is included in Figure 1 of the main text.

Oceania: Oceania was not included due to time-zone and sample size issues. 


\subsection{Appendix D: User totals for 44 countries per day of the week}

\begin{tabular}{|c|c|c|c|c|c|c|c|c|}
\hline & Sunday & Monday & Tuesday & Wednesday & Thursday & Friday & Saturday & Total Result \\
\hline Algeria & 339 & 340 & 311 & 337 & 323 & 320 & 323 & 2293 \\
\hline Angola & 216 & 279 & 277 & 277 & 313 & 285 & 219 & 1866 \\
\hline Cambodia & 272 & 265 & 244 & 262 & 277 & 289 & 280 & 1889 \\
\hline Cameroon & 195 & 233 & 222 & 226 & 223 & 210 & 212 & 1521 \\
\hline Colombia & 139 & 129 & 153 & 140 & 147 & 139 & 136 & 983 \\
\hline Côte d'lvoire & 181 & 183 & 166 & 194 & 205 & 175 & 155 & 1259 \\
\hline Czech Republic & 114 & 125 & 117 & 125 & 142 & 122 & 115 & 860 \\
\hline Egypt & 515 & 470 & 512 & 525 & 516 & 520 & 526 & 3584 \\
\hline Ethiopia & 835 & 841 & 851 & 851 & 852 & 899 & 846 & 5975 \\
\hline France & 191 & 176 & 200 & 203 & 194 & 210 & 171 & 1345 \\
\hline Germany & 294 & 264 & 235 & 261 & 255 & 243 & 246 & 1798 \\
\hline Ghana & 185 & 181 & 185 & 192 & 201 & 172 & 173 & 1289 \\
\hline Guinea & 152 & 135 & 147 & 157 & 148 & 158 & 164 & 1061 \\
\hline Hong Kong & 161 & 152 & 137 & 154 & 161 & 152 & 138 & 1055 \\
\hline |taly & 203 & 210 & 205 & 226 & 194 & 222 & 219 & 1479 \\
\hline Japan & 339 & 348 & 355 & 348 & 320 & 312 & 326 & 2348 \\
\hline Kenya & 97 & 109 & 103 & 108 & 120 & 130 & 118 & 785 \\
\hline Kyrgyzstan & 203 & 180 & 185 & 204 & 206 & 193 & 189 & 1360 \\
\hline Liberia & 139 & 112 & 121 & 139 & 137 & 135 & 129 & 912 \\
\hline Libya & 205 & 204 & 218 & 210 & 189 & 256 & 214 & 1496 \\
\hline Mali & 204 & 203 & 197 & 212 & 204 & 216 & 222 & 1458 \\
\hline Nigeria & 751 & 737 & 745 & 816 & 809 & 780 & 756 & 5394 \\
\hline Oman & 129 & 128 & 135 & 137 & 128 & 131 & 137 & 925 \\
\hline Pakistan & 823 & 770 & 763 & 822 & 795 & 828 & 817 & 5618 \\
\hline Philippines & 1433 & 1413 & 1462 & 1509 & 1589 & 1494 & 1510 & 10410 \\
\hline Poland & 133 & 139 & 118 & 134 & 125 & 129 & 113 & 891 \\
\hline Saudi Arabia & 562 & 560 & 523 & 565 & 541 & 566 & 509 & 3826 \\
\hline Senegal & 254 & 256 & 268 & 292 & 258 & 283 & 280 & 1891 \\
\hline Somalia & 394 & 398 & 361 & 387 & 381 & 373 & 362 & 2656 \\
\hline South Africa & 128 & 149 & 152 & 119 & 134 & 142 & 136 & 960 \\
\hline South Korea & 202 & 177 & 192 & 213 & 189 & 163 & 172 & 1308 \\
\hline South Sudan & 215 & 232 & 213 & 232 & 247 & 233 & 236 & 1608 \\
\hline Spain & 207 & 231 & 204 & 241 & 210 & 203 & 197 & 1493 \\
\hline Sudan & 652 & 649 & 665 & 719 & 686 & 700 & 666 & 4737 \\
\hline Taiwan & 331 & 243 & 255 & 272 & 279 & 280 & 310 & 1970 \\
\hline Tajikistan & 240 & 258 & 252 & 274 & 266 & 273 & 233 & 1796 \\
\hline Thailand & 542 & 446 & 464 & 488 & 517 & 552 & 503 & 3512 \\
\hline Turkey & 366 & 359 & 334 & 386 & 368 & 374 & 345 & 2532 \\
\hline Turkmenistan & 531 & 505 & 517 & 570 & 573 & 566 & 538 & 3800 \\
\hline UAE & 220 & 248 & 252 & 270 & 260 & 243 & 252 & 1745 \\
\hline United Kingdom & 375 & 375 & 404 & 385 & 397 & 387 & 351 & 2674 \\
\hline Uzbekistan & 1471 & 1513 & 1507 & 1605 & 1569 & 1596 & 1477 & 10738 \\
\hline Metnam & 248 & 227 & 223 & 231 & 223 & 207 & 216 & 1575 \\
\hline Yemen & 164 & 148 & 146 & 183 & 163 & 135 & 166 & 1105 \\
\hline Total Result & 15550 & 15300 & 15296 & 16201 & 16034 & 15996 & 15403 & 109780 \\
\hline
\end{tabular}

